\title{
Summer Quarter in Puebla, Mexico
}

Sarah Behm

BCRP Student

City and Regional Planning Department

Cal Poly San Luis Obispo

Being able to spend a whole summer studying at the Benemerita Universidad Autonoma de Puebla, in Mexico, and participating in the joint effort of this university with the CRP department are two of the advantages with is international exchange agreement. Once experienced, these are experiences that change your perspectives of live and of your profession.

Currently I am a $4^{\text {th }}$ year City and Regional Planning student at California Polytechnic State University. Until this last summer I was the average student in our department. I had a typical internship with a government agency and kept myself busy with school, student clubs, and friends. However, now I am proud to say I have been exposed to a new way of living and thinking. I am no longer the average city and regional planning senior, and my resume is no longer identical to the rest.

For a little over three months during the summer, I participated in a departmental exchange program in Puebla, Mexico. The City of Puebla is located approximately 80 miles southeast of Mexico City at an elevation of 7,000

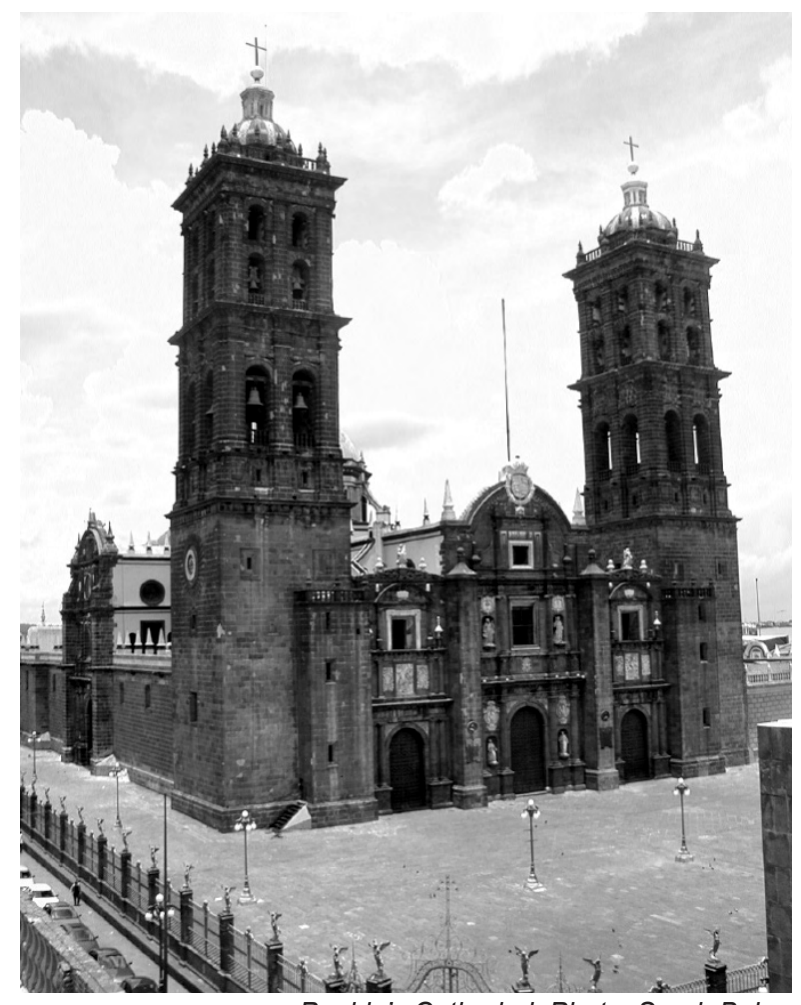

Puebla's Cathedral. Photo: Sarah Behm feet. When I was about to board the plane heading off to this large Mexican city of 1,346,000 inhabitants, I felt a strange mix of fear, excitement, and uncertainty churning inside. At the University I would attend, Benemerita Autonoma Universidad de Puebla (BUAP), there would be a large number of students who only speak Spanish. How would I be accepted by them? How would I adjust to a new lifestyle? Many questions scattered through my mind, but within my first week they were all answered positively.

When I arrived to Puebla, I immediately felt welcomed. During my stay, I lived with two different Mexican families, where I experienced two different ways of living, communicating, cooking, celebrating, and loving one another. Both families were so accepting I felt like an adopted daughter. The students and professors at the University were equally accepting, and went out of their way to make me feel at home, a cultural characteristic we usually don't see in America.

The city itself was also easily accessible and pedestrian friendly. I quickly learned the bus system in order to get to school and to the city's central area where I was exposed to the spatial and architectural expressions of their deeply rooted

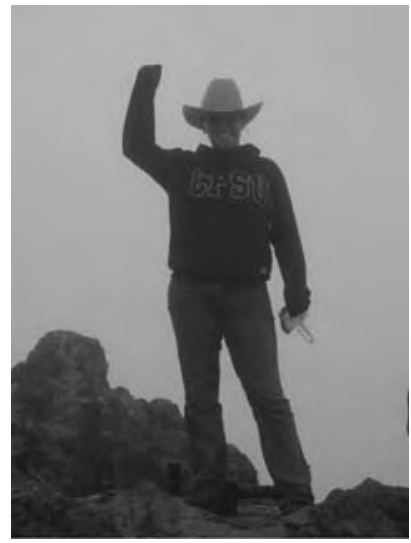

Sarah Behm in Puebla 


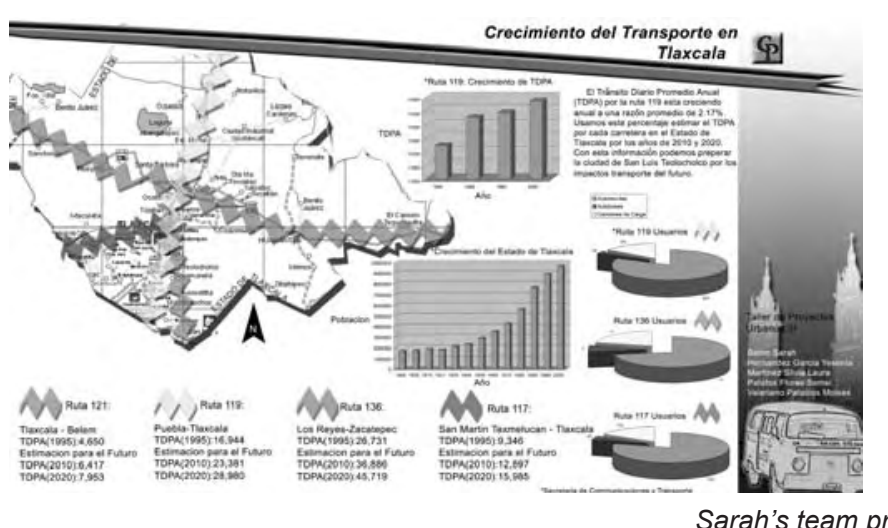

Sarah's team project in Puebla.

culture. Here I noticed the importance of caring, religion, and humor in Mexican culture through the interactions of people and the layout of the commercial districts, which are designed to integrate religion, history, business, and entertainment. There wasn't one city I visited in Mexico without a "zocalo" or central core. Just as Mexicans hold their families close to their hearts, they also find it essential to build a heart of a city where the community can come together as one. Located in these central areas are generally main government offices and large plazas used daily for either strolling or special celebrations, as seen in the picture of the main church and central plaza in the heart of Puebla.

Aside from living and traveling, I found my most beneficial experiences inside the classroom at BUAP. Through my courses, I was exposed to not only a new language, but also to new theories and perspectives on urban planning. I participated in two design labs, each with a main focus to create a sense of place within a location that tied directly to its history of use. This was particularly important in one lab where we conducted a transportation design study for a small community (see figure). The other lab focused on creating a strong vision and central theme for our selected site, which would later be used for our final design, as was heavily emphasized by the professors. In working with both my groups I thoroughly enjoyed expanding my mind to new ways of planning, processing, and expressing information. Both groups were also very open to combining educational techniques and solutions in order to produce an innovative result.

The other two courses I participated in were Urban Law and Urban Ecology, in which I was exposed to the evolution of planning in Mexico. Currently there are many laws existing

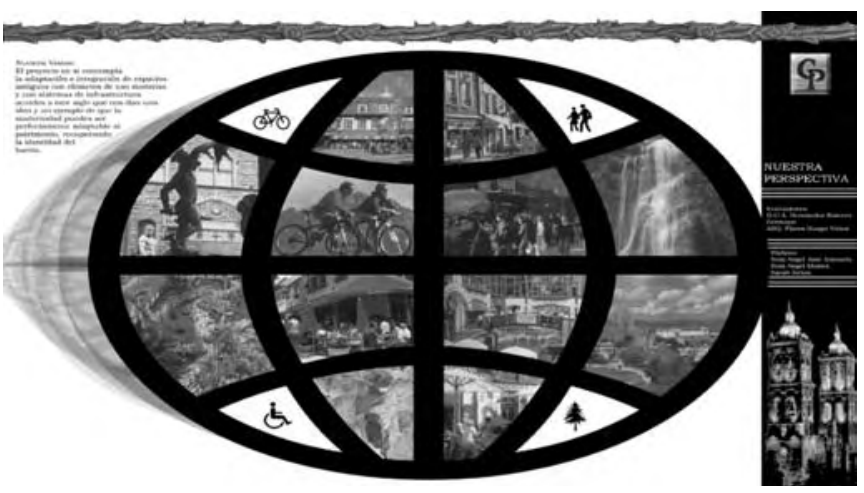

in Mexico to regulate the environment and other planning issues, but they are rarely implemented correctly, and sometimes not implemented at all. After being immersed in a classroom setting, I perceived a strong pressure being put on students to protect the environment through stricter laws and regulations. I am sure that when these students enter their careers they will help strengthen environmental protection policies, which is much needed in Mexico.

My trip benefited my future in many ways. Not only am I able to speak Spanish in a U.S. state where over half of its population is from a Latin background, but I am also able be more open and respectful to the ideas of people from different backgrounds. I feel that living amongst different cultures is essential for any planning education. An opportunity to study planning in another country can allow us to look at the same planning problems we have been studying throughout our college careers in a whole new light. These new perspectives, places, and experiences can expand our planning knowledge, constructing openings to new waterfalls, rivers, and streams of knowledge from minds across the globe. 